Plant Tissue Cult. \& Biotech. 29(2): 175-184, 2019 (December)

CBangladesh Assoc. for Plant Tissue Culture \& Biotechnology $\overline{\text { PTC\&B }}$

\title{
Efficient Clonal Propagation of Musa sp. paradisiaca Cultivar Gopi and Clonal fidelity Assessment Using ISSR Marker
}

\author{
Rabindra Kumar Sinha*, Puja Rani Saha, Bibhash Nath, H. Reshmi \\ Singha, Anath Bandhu Das ${ }^{1}$, Satyanarayan Jena ${ }^{2}$ and Sangram Sinha \\ Cytogenetics and Plant Biotechnology Laboratory, Department of Botany, Tripura University, \\ Suryamaninagar-799022, Tripura, India
}

Key words: Musa, Cultivar Gopi, Micropropagation, Clonal fidelity, ISSR marker

\begin{abstract}
Attempt was made towards optimizing an in vitro shoot multiplication of banana cultivar Gopi with subsequent assessment of genetic stability. Experiments on enhanced shoot multiplication were conducted in MS fortified with BAP, Kn and 2-iP (4 mg $\Lambda$ ) for a period of 8 weeks. Administration of exogenous root inducing growth regulator was eliminated to reduce culture investment and economy. Treatment with BAP supplemented medium proved to be optimum for shoot multiplication whereas 2-iP produced satisfactory results for shoot elongation. Long term incubation in all the treatments had been favorable for developing efficient root system. Hardening of in vitro grown plantlets showed high rate of survival (95\%) upon transfer to potted soil. Assessment of clonal fidelity through inter simple sequence repeats (ISSR) analysis revealed $100 \%$ uniformity.
\end{abstract}

\section{Introduction}

Banana is a major fruit crop with multidimensional roles ranking as the fourth most crucial global food commodity in terms of gross production (FAO 2001, INIBAP 1992). As an important food and fruit crop, banana not only potentially contributes to the food security of a large number of people all over the world. It has also a definite role in uplifting and affecting the economic status of innumerable rural small holders in agricultural countries like India (Mahalakshmi et al. 2016). Moreover, the banana plant

*Author for correspondence: < khsinhark@yahoo.co.in>. 'Department of Botany, Utkal University, Bhubaneswar, Odisha, India. ${ }^{2}$ Genetics and Molecular Biology, CSIR-National Botanical Research Institute, Lucknow, Uttar Pradesh, India.

DOI: https://doi.org/10.3329/ptcb.v29i2.44506 
has been inevitably holding a sacred position in Indian cultural heritage from the ancient times. India is known to be one of the centers of origin of Musa (Stover and Simmonds 1987) where north-eastern states cover an astounding diverse natural Musa population.

Among them, Tripura is an exclusive address to numerous cultivated bananas like Sobri, Chapa, Kaanch kola and Gopi which have been under local cultivation practices by small scale farmers since long time. Musa $\times$ paradisiaca L. cultivar Gopi is a well-known cultivar which has certainly developed as a good commercial banana among the people of this region owing to its better yield potential, sweet taste and utilities in holy purposes. But the plantation and cultivation programmes of this particular cultivar in this region are inadequate to meet the ever increasing demands of the local people and also its developing export potential. In addition, large scale production, maintenance of existing banana plantation is challenged by numerous limiting factors like high susceptibility to pathogens (Persley and De Langhe 1987), poor suckering ability (Ndubizu 1985), pests and diseases, poor agronomic practices and post-harvest constraints (Robinson 1996). Under the circumstances, in vitro micropropagation may prove to be dependable to overcome the limiting constraints for commercial mass propagation of disease free and true to type planting material of Musa $\times$ paradisiaca cultivar Gopi. Since tissue culture method is a sophisticated technique, it does not always confirm to be economically viable (Tomar et al. 2007). So, a necessary approach in the possible minimization of culture requirements becomes imperative for cost effective, cheap, fast and simple technique of optimum healthy banana production. Two important criteria of successful in vitro rapid propagation of banana are efficient development of multiple shoots and generation of genetically homogenous and uniform plantlets. Cytokinins have been known to induce high frequency in vitro shoot regeneration and multiplication in banana (Buah et al. 2000 and 2010). Application of different plant growth regulators during the culture and changes in habituations are known to be associated with genetic instability of the plants. Therefore, identification of somaclonal variations is regarded as important steps for quality control in tissue culture produced plant (Soniya et al. 2001). Various methods can be used to detect the genetic stability of regenerated plant but the most reliable method is to use molecular markers. Molecular markers are considered as a suitable method to detect the genetic variability among the plants (Zerihum et al. 2009). Among the molecular markers, Inter Simple Sequence Repeats (ISSR) marker is considered as dominant markers (Tsumura et al. 1996). It is cost effective and highly reliable method in genetic variability study (Borba et al. 2005). Study on somaclonal variations of banana using ISSR markers has also been reported by several researchers (Rout et al. 2009, Ying et al. 2011, Choudhury et al. 2015, Nandhakumar et al. 2017). The present study is an attempt towards optimizing a suitable in vitro mass multiplication method of Musa cultivar Gopi emphasizing on the reduction of culture needs like use of growth regulators and subculture phases and also subsequent assessment of clonal fidelity with ISSR markers. 


\section{Materials and Methods}

An in vitro clonal propagation protocol has been established for the Musa sp. cultivar Gopi through multiple shoot induction focusing on sterilization steps and explant preparation following Sinha et al. 2018. To ensure efficient in vitro mass propagation of Gopi using long term subculture phase minimizing the application of growth regulator and also to assess the clonal fidelity of the regenerants using ISSR markers, present study was conducted.

Mass propagation of clones and maintenance of banana cultivar Gopi was achieved in prolonged subculture phase in MS with BAP, Kn and 2-iP. Well-developed shoot clusters were subcultured into fresh MS supplemented with $4 \mathrm{mg} \wedge \mathrm{BAP}, \mathrm{Kn}$ and 2-iP and kept in prolonged incubation of culture for 8 weeks without any further intervening subculture. Observation on number of shoots per cluster, number of leaves per shoot, number of roots per shoot, shoot size $(\mathrm{cm})$, leaf size including length $(\mathrm{cm})$ and width $(\mathrm{cm})$ and root size $(\mathrm{cm})$ were recorded after 8 weeks. A mean of five replicates of shoot clusters were used in each treatment. Root inducing growth regulator was not applied in the subsequent stages to simplify the culture needs and produce a possible cost effective method. After 8 weeks of culture, the elongated shoots with well-developed root system were detached carefully from the base of the shoot cluster with a sterilized scalpel and thoroughly washed with water. The regenerated clones were finally placed in tap water ex vitro for a few days. This was followed by transferring the in vitro grown plantlets to potted soil mix (Soil : sand : soilrite $=2: 1: 1$ ) in the shade house with relative humidity of $70 \%$ and $16 \mathrm{hrs} /$ day photoperiod for the purpose of hardening. Confirmation of genetic stability of the in vitro raised banana plantlets of the present cultivar becomes imperative for the employment of the current method in future micropropagation programmes. For this purpose, molecular fingerprinting analysis using 11 ISSR primers was conducted with five randomly selected culture derived banana plants to compare with the mother plant.

Total genomic DNA was isolated from young tender leaves of mother plant growing in the garden as well as in vitro raised banana plant following the protocol of DNeasy ${ }^{\circledR}$ Plant Mini Kit-Qiagen (Part no.69104). The purity, size and integrity of DNA were determined by using a $0.8 \%$ agarose gel stained with ethidium bromide (EtBr) using gelpilot $1 \mathrm{~kb}$ plus ladder.

Amplification of DNA was carried out with 11 ISSR primers using a VeritiTM96 well thermal cycler (Applied Biosystems by Thermo Fisher Scientific). PCR was performed with $25 \mu$ reaction mixture containing genomic DNA ( $30 \mathrm{ng} / \mu \mathrm{l}$, measured by Nanodrop 2000c spectrophotometer), 10 mMdNTPs (Qiagen), 10X Taq buffer with $15 \mathrm{mM} \mathrm{MgCl} 2$

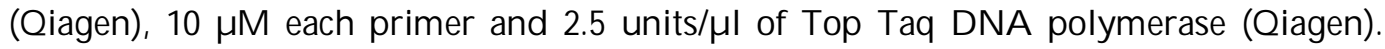
Amplification was carried out with initial temperature of $94^{\circ} \mathrm{C}$ for $5 \mathrm{~min}$ to denature the DNA followed by 44 cycles having three temperature ranges: $94^{\circ} \mathrm{C}$ for $1 \mathrm{~min}$ with varied temperatures as per melting temperatures of ISSR primers and $72^{\circ} \mathrm{C}$ for primer extension 
followed by $72^{\circ} \mathrm{C}$ for $20 \mathrm{~min}$. Amplification reaction was performed two times for each ISSR primer. Amplified DNA fragments were separated on 2\% agarose gel electrophoresis stained with ethidium bromide $(\mathrm{EtBr})$ and gels were visualized through gel documentation system (XR +, Bio-Rad).

The amplified DNA fragments generated by ISSR primers were scored with binary values ' 1 ' for presence and ' 0 ' for absence. Only clear and reproducible bands were scored. Binary data were used to calculate the level of monomorphism and polymorphism for each primer.

The data on different morphogenetic responses were expressed as mean $\pm \mathrm{Sd}$ of five replicates per treatment and subjected to one-way ANOVA followed by DMRT at $\mathrm{p}<$ 0.05 for comparison to reveal any possible significant differences.

\section{Results and Discussion}

Simplification of culture needs by lengthening the period of culture incubation in MS supplemented with BAP, $\mathrm{Kn}, 2$-iP in a particular concentration (4 mg/) was carried out in the present study. Long term culture of in vitro derived shoot clusters subjected to the treatments revealed visible shoot multiplication differences and also a good response of root induction. Rate of shoot multiplication was better achieved in culture medium fortified with BAP (Fig. 1A) compared to other two treatments of Kn (Fig. 1B) and 2-iP (Fig. 1C). Maximum number of shoots was recorded in BAP supplemented media with an average shoot number of $8.00 \pm 2.00$ per cluster. This was followed by media containing $\mathrm{Kn}$ and 2-iP, respectively. However, effect of 2-iP treatment exhibited increased shoot growth $(8.27 \pm 0.89) \mathrm{cm}$ in comparison to other two cytokinins (Table 1$)$.

Relative superiority of BAP in shoot multiplication was also reported by many workers (Kim et al. 2003, Mishra and Chakraborty 2009, Mahmood and Hauser 2015). Potential of BAP in induction of shoot formation from meristematic explants in banana has been well documented in earlier works (Buah et al. 2010, Ferdous et al. 2015). Similar trend of high frequency in vitro shoot induction in BAP supplemented media followed by Kn was observed for banana cv. Grand Naine by Yadav et al. (2017). Observations on other relevant morphometric characters like mean number of leaves per shoot and mean leaf size revealed almost similar range of values. Although the treatment of $\mathrm{Kn}$ supplemented media yielded minimum mean number of leaves per shoot $(3.37 \pm 0.13)$ but has resulted in better growth of leaves in terms of size $(3.48 \pm 0.63 \times 1.49 \pm 0.31) \mathrm{cm}^{2}$ in comparison to other two treatments. Prolonged culture ( 8 weeks) in cytokinin enriched medium supported spontaneous root induction and growth without any supply of exogenous root inducing growth regulators which has been substantial with respect to simplification of culture needs. Root induction and production in all the treatments of cytokinin produced almost similar range of values for mean number of roots and root size (Table 1). Prolific rooting of the shooting clusters in almost all the treatments for long term culture incubation suggests facultative or non-obligatory use of root inducing 
hormone for this particular banana cultivar. However, certain in vitromorphogenic response may result from endogenous accumulation of auxin or due to stress (Feher et al. 2001, Cueva Agila et al. 2013) and the same factors may be responsible for the development of roots in the present experiment. Relatively higher mean root size was recorded in media supplemented with $\mathrm{Kn}$ followed by 2-iP and BAP respectively.

Table 1. Morphometric characters of Musav sp. cultivar Gopi for 8 weeks in MS with BAP, Kn and 2-iP.

\begin{tabular}{lccc}
\hline $\begin{array}{l}\text { Morphometric characters } \\
\left({ }^{*} \text { Mean } \pm \mathrm{Sd}\right)\end{array}$ & \multicolumn{3}{l}{ Treatment with cytokinins $(4 \mathrm{mg} \Lambda)$} \\
\cline { 2 - 4 } & BAP & Kn & $2-\mathrm{iP}$ \\
\hline No. of shoots & $8.00 \pm 2.00^{\mathrm{a}}$ & $6.60 \pm 2.41^{\mathrm{a}}$ & $5.40 \pm 1.34^{\mathrm{a}}$ \\
& $(6.00-11.00)$ & $(4.00-10.00)$ & $(4.00-7.00)$ \\
No. of leaves & $4.53 \pm 0.65^{\mathrm{b}}$ & $3.37 \pm 0.13^{\mathrm{c}}$ & $4.54 \pm 0.92^{\mathrm{b}}$ \\
& $(3.90-5.57)$ & $(3.30-3.60)$ & $(3.50-6.00)$ \\
No. of roots & $4.43 \pm 0.90^{\mathrm{d}}$ & $4.76 \pm 1.04^{\mathrm{d}}$ & $4.57 \pm 0.28^{\mathrm{d}}$ \\
& $(3.33-5.71)$ & $(3.40-6.00)$ & $(4.33-5.00)$ \\
Size parameters $(\mathrm{cm})$ & & & \\
Shoot size & $6.51 \pm 1.23^{\mathrm{e}}$ & $7.58 \pm 0.99^{\mathrm{ef}}$ & $8.27 \pm 0.89^{\mathrm{f}}$ \\
& $(5.01-7.88)$ & $(6.46-8.75)$ & $(7.33-9.37)$ \\
Leaf length & $3.15 \pm 0.71^{\mathrm{g}}$ & $3.48 \pm 0.63^{\mathrm{g} 3}$ & $0.32 \pm 0.25^{\mathrm{g}}$ \\
& $(1.99-3.89)$ & $(2.70-4.15)$ & $(3.07-3.67)$ \\
Leaf width & $1.45 \pm 0.27^{\mathrm{h}}$ & $1.49 \pm 0.31^{\mathrm{h}}$ & $1.29 \pm 0.15^{\mathrm{h}}$ \\
& $(0.97-1.63)$ & $(1.06-1.74)$ & $(1.11-1.47)$ \\
Root size & $5.38 \pm 0.91^{\mathrm{i}}$ & $6.09 \pm 1.19^{\mathrm{i}}$ & $5.85 \pm 0.45^{\mathrm{i}}$ \\
& $(3.87-6.21)$ & $(4.86-7.50)$ & $(5.33-6.59)$ \\
\hline
\end{tabular}

*Mean of five shoot clusters; Data represent mean \pm Sd followed by different letters for significant difference within the rows using one way ANOVA and DMRT at $p<0.05$; in parentheses range of minimum and maximum values.

In fact rooting at varying levels was found to occur in all the regenerated shoots without any exogenous input of auxin in long term culture. Development of root system ofthe elongated shoots was efficient and vigorous (Fig. 1F). In contrast, normal and rapid rooting of in vitro shoots was successfully achieved in media with IAA $(2.00 \mathrm{mg} /)$ within a week of culture (Fig. 1E). Necessity of auxin application for better rooting of banana cultivars has been reported in previous works (Madhulata et al. 2006, Safarpour et al. 2017). Hardening of the in vitro regenerants in field conditions was successful with high survival rate and they were also healthy with no morphological abnormalities (Fig. 1G). Subsequent confirmation of genetic stability of the in vitro raised plantlets with the mother plant was carried out through ISSR markers which revealed true to type clonal nature. True to type plantlets with no genetic or morphological alteration is the outcome of a successful micropropagation protocol (Prakash et al. 2016, Safarpour et al. 2017). 
Moreover, commercial banana production necessitates the testing of genetic stability of in vitro raised plantlets. Molecular fingerprinting analysis using 11 ISSR primers was done to check the genetic stability of five randomly selected culture derived banana plants and to compare them with the mother plant. Eleven primers revealed a total of 84 numbers of bands with an average 7.64 number bands per primer. The number of score
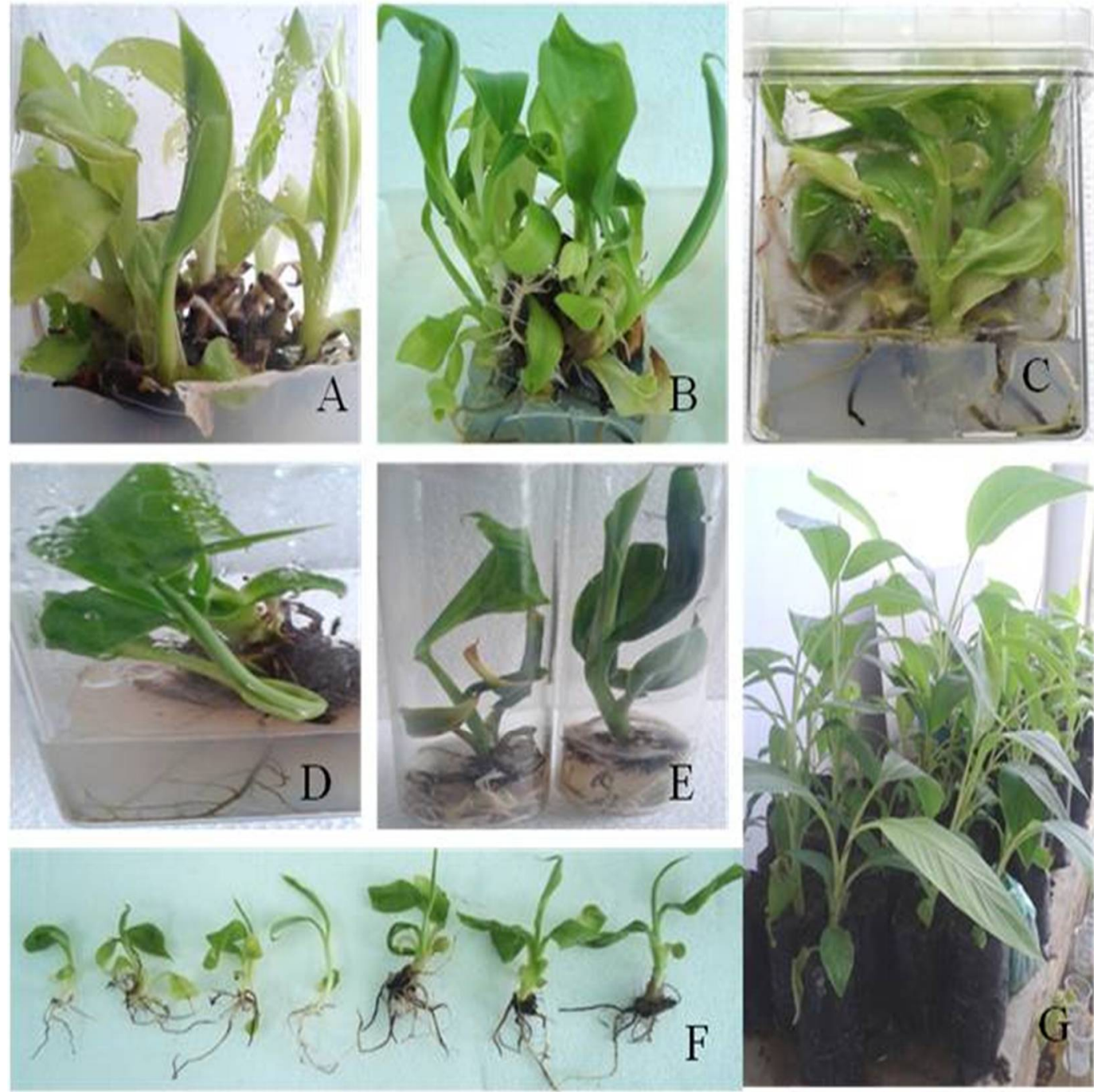

Fig. 1. Shooting clusters raised in prolonged culture in MS containing $4 \mathrm{mg} /$ (A) BAP, (B) 2iP and

(C) $\mathrm{Kn}$, (D) rooting of shoots in media containing low 2iP, (E) normal rooting of shoots in media containing IBA $(2 \mathrm{mg} /)$, $(\mathrm{F})$ rooted clones of the shoot cluster generated without any exogenous root inducing growth regulator and $(G)$ successful hardening of the clones in potted soil. 
bands per primer varied from 4 to 12 with 504 number of total amplified bands (Table 2). The maximum number of amplified band was recorded in UBC 808 with 72 numbers of bands (Fig. 2). Results of the present study indicated no detectable variation in the in vitro obtained clones of the banana cultivar Gopi through ISSR analysis. No polymorphism was detected among all the regenerated plants. Absence of genetic variability in tissue culture produced banana cultivar using ISSR markers has also been reported by Lakshmanan et al. (2007). However, some authors have reported genetic, epigenetic and phenotypic changes which occur during the in vitro regeneration process (Sharma et al. 2011, Singh et al. 2012). Somaclonal variation of culture derived banana cultivars was also reported by Nandhakumar et al. (2017).

Table 2. Banding pattern of ISSR primers among five randomly selected micropropagated and mother plants of Musa sp. cultivar Gopi.

\begin{tabular}{llllllc}
\hline $\begin{array}{l}\text { ISSR } \\
\text { primers }\end{array}$ & $\begin{array}{l}\text { Primer sequence } \\
\left(5^{\prime}-3^{\prime}\right)\end{array}$ & NSB & MB & PB & PMB & $\begin{array}{l}\text { Total number of } \\
\text { amplified bands }\end{array}$ \\
\hline UBC 808 & $(\mathrm{AG})_{8} \mathrm{C}$ & 8 & 8 & 0 & 100 & 48 \\
UBC 815 & $(\mathrm{CT})_{8} \mathrm{~T}$ & 5 & 5 & 0 & 100 & 30 \\
UBC 824 & $(\mathrm{TC})_{8} \mathrm{G}$ & 8 & 8 & 0 & 100 & 48 \\
UBC 840 & $(\mathrm{GA})_{8}$ YT & 11 & 11 & 0 & 100 & 66 \\
UBC 849 & $(\mathrm{GT})_{8}$ CG & 6 & 6 & 0 & 100 & 36 \\
UBC 855 & $(\mathrm{AC})_{8}$ YT & 4 & 4 & 0 & 100 & 24 \\
UBC 864 & $(\mathrm{ATG})_{6}$ & 8 & 8 & 0 & 100 & 48 \\
UBC 880 & $(\mathrm{GGAGA})_{3}$ & 12 & 12 & 0 & 100 & 72 \\
HB 15 & $(\mathrm{GTG})_{3} \mathrm{GC}$ & 9 & 9 & 0 & 100 & 54 \\
ISSR 67 & $(\mathrm{TC})_{7} \mathrm{CC}$ & 4 & 4 & 0 & 100 & 24 \\
ISSR Y11 & $(\mathrm{GA})_{8} \mathrm{~T}$ & 9 & 9 & 0 & 100 & 54 \\
Total & & 84 & 84 & 0 & 1100 & 504 \\
Mean & & 7.64 & 7.64 & 0 & 100 & 45.82 \\
\hline
\end{tabular}

NSB - Number of score band, PB - Polymorphic band, MB - Monomorphic band, PMB - Percentage of monomorphic band.

All the amplified bands of culture derived banana plants were homogenous and monomorphic in nature. Molecular fingerprinting study using ISSR markers of tissue culture derived plant revealed similar banding pattern with the mother plant. The result indicated that, ISSR primer could be useful for detecting genetic stability of in vitro raised banana plant. Therefore, clonal fidelity analysis of in vitro propagated banana plants revealed clonal in nature. Findings of the present study highlight on manifestation of long term incubation culture method for mass multiplication of Musa sp. cultivar Gopi through a different outlook of economic and labour feasibility. Reduction of certain obligatory requisites of culture method like subculture phases, exogenous supplementation of rooting hormone and omitting the rooting phase in root inducing 

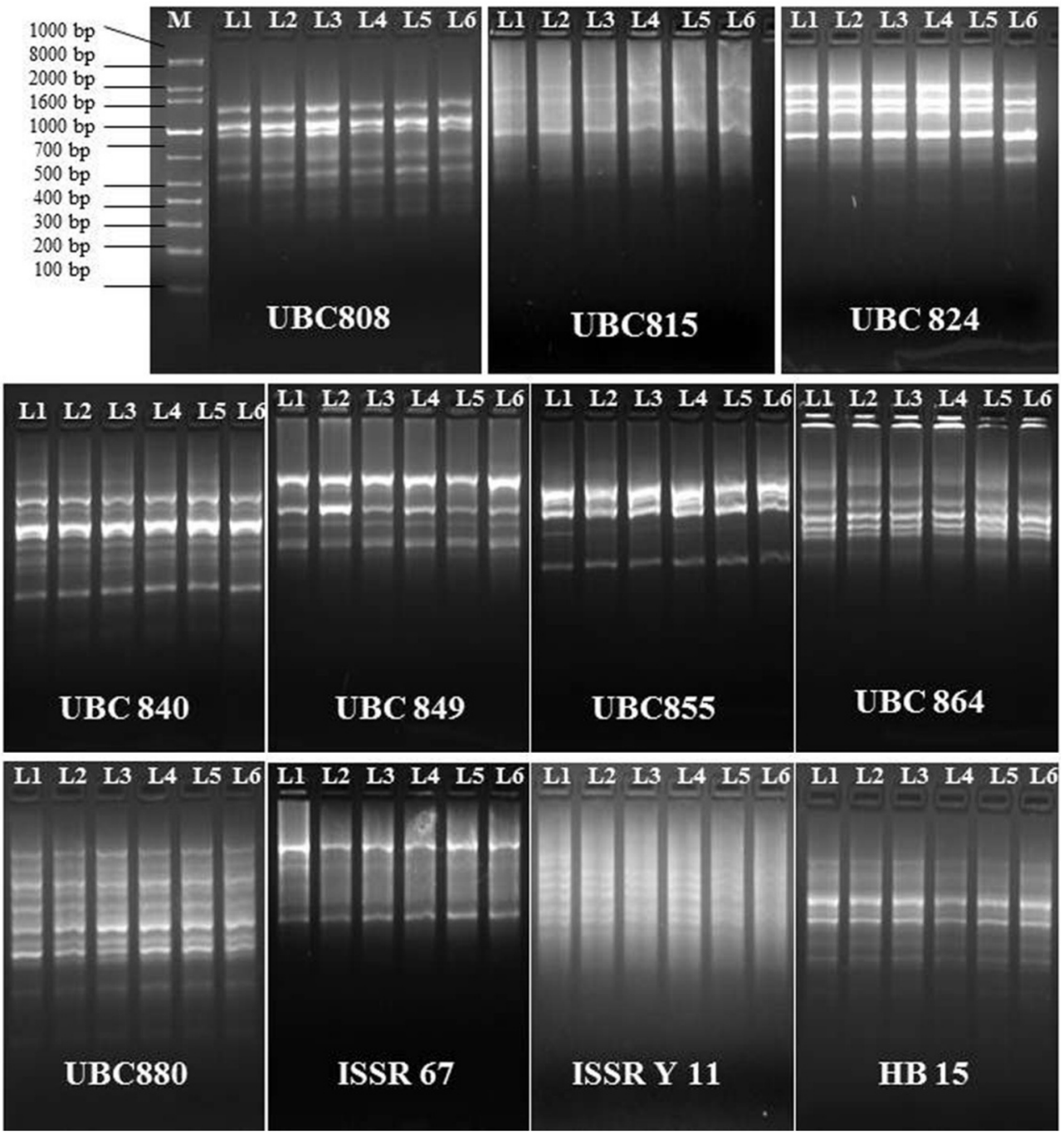

Fig. 2. ISSR profile of five randomly selected micropropagated and control plant of Musa sp. cultivar Gopi where, M represents $1 \mathrm{~kb}$ plus ladder, L1 - L5 represent five regenerated plants and L6 represents mother plant.

plant growth regulator along with high survival rate is profitable concerning the sophisticated requirements of tissue culture. In addition, establishment of genetic fidelity of the in vitro clones revealed by ISSR analysis suggests the suitability of the current method to produce true-to-type banana plantlets without any risk and consequent mass propagation of Musa sp. cultivar Gopi for preservation, food security and utilization in commercial industry. 


\section{Acknowledgements}

Department of Biotechnology (DBT), Govt. of India provided financial support through a project (No. BCIL/NER-BPMC /2018/245).

\section{References}

Borba RS, Garcia MAS, Kovalleski A and Oliveira, AC (2005) Dissimilaridadegenética de linhagens de TrichogrammaWestwood (Hymenoptera: Trichogrammatidae) através de marcadoresmoleculares ISSR. Neotrop. Entomol. 34:11.

Buah JN, Danso E, Taah KJ, Abole EA and Asiedu, J (2010) The effect of different concentrations of cytokinins on the in vitro multiplication of plantain (Musa sp.). Biotechnol. 9: 343-347.doi: 10.3923 biotech.2010.343.347.

Buah JN, Kawamitsu Y, Yonemori S and Murayama S (2000) Field performance of in vitro propagated and sucker derived plants of banana (Musa spp.).Plant Prod. Sci. 3: 124128.https://doi.org/10.1626/pps.3.124.

Choudhury D, Kajla S, Poonia AK, Brar B and Surekha Duhan JS (2015) Molecular assessment of genetic stability using ISSR and RAPD markers in in vitro multiplied copies of commercial banana cv. Robusta. Indian J. Biotechnol. 14: 420-424.

Cueva Agila AY, Guachizaca I and Cella R (2013) Combination of 2, 4-D and stress improves indirect somatic embryogenesis in Cattleya maxima Lindl. Plant Biosyst. 149: 235241.https://doi.org/10/1080/11263504.2013.797033.

FAO (2001) On-line database of the Food and agricultural Organization of the UnitedNations. Available online: http://apps. Fao. org/default.html.

Feher A, Pasternak T, Miskolczi P, Ayaydin F and Dudits D (2001) Induction of the embryogenic pathway in somatic plant cells. Acta Hort. 560: 293-298.

Ferdous MH, Billah AAM, Mehraj H, Taufique T and Uddin AFM (2015) BAP and IBA pulsing for in vitro multiplication of banana cultivars through shoot tip culture. J. Biosci. Agri. Res. 3(2): 87-95.

INIBAP (1992) International network for the improvement of banana and plantain. Annual report. Montpellier, France, pp. 40.

Kim CK, Oh JY, Jee SOand Chung JD (2003)In vitro micropropagation of Rosa hybrid L. J. Plant Biotechnol. 5: 115-119.

Lakshmanan V, Venkataramareddy SR and Neelwarne B (2007) Molecular analysis of genetic stability in long-term micropropagated shoots of banana using RAPD and ISSR markers. Electronic J. Biotech. 10: 1.

Madhulata P, Kirubakaran SI andSakthivel N (2006) Effects of carbon sources and auxins on in vitro propagation of banana. Biologia Plantarum 50: 782-784.

Mahalakshmi C, Kumar SV, Maneesh, P and Fathima, JSA (2016) An analysis of banana cultivation in Theni District, Tamil Nadu. Indian J. Economics and Development. 4(9).

Mahmood S and Hauser B (2015) Influence of cytokinins on the shoot proliferation and subsequent rooting in rose. Asian J. Agricultural Res. 9(5): 259-267.

Mishra P and Chakraborty D (2009) Clonal propagation of Rosa clinophylla Thory through axillary bud culture. Scientia Horticulturae 119: 212-216. 
Nandhakumar N, Soorianathasundaram KD, Sudhakar D and Kumar KK (2017) Genetic fidelity analysis in the micropropagated banana derived from immature primordial male flower bud. Int. J. Curr. Microbiol. App. Sci. 6(4): 1759-1769. https://doi.org/10.20546/jicmas. 2017. 604.211.

Ndubizu TOC (1985) Plantain production manual for Nigerian growers. Imo State College of Agriculture. Umuagwo. Technical bulletin. 1. pp. 25.

Persley GJ and De Langhe E (1987) Banana and plantain breeding strategies. ACIAR Proceedings no. 21. pp. 87.

Prakash L, Middha SK, Mohanty SK and Swamy MK (2016) Micropropagation andvalidation of genetic and biochemical fidelity among regenerants of Nothapody tesnimmoniana (Graham) Mabb. Employing ISSR markers and HPLC. 3Biotech. 6:1-9.DOI: 10.1007/\$13205-016-0490-y.

Robinson JC (1996) Bananas and Plantains, CAB. International, UK, pp. 238.

Rout GR, Senapati SK, Aparajita S and Palai SK (2009) Studies on genetic identification and genetic fidelity of cultivated banana using ISSR markers. Plant Omics 2 (6): 250-258.

Safarpour M, Sinniah UR, Subramaniam S and Swamy MK (2017)A novel technique for Musa acuminata Colla 'Grand naine' (AAA) micropropagation through transverse sectioning of shoot apex. In vitro Cell. Dev. Biol-Plant. 53(3): 226-238.https://doi.org/10.1007/\$11627-017-9809-6.

Sharma S, Pamidimarri DVNS, Ananda KGV and Reddy MP (2011) Assessment ofgenetic stability in micropropagules of Jatropha curcas genotypes by RAPD and AFLP analysis. Ind. Crops Prod. 34: 1003-1009.

Singh SK, Rai MKand Sahoo L (2012) An improved and efficient micropropagation of Ecliptaalba through transverse thin cell layer culture and assessment of clonal fidelity using RAPD analysis .Ind. Crops Prod. 37: 328-333.

Sinha RK, Saha PRS, Das AB, JenaSN and Sinha S (2018) In vitro clonal propagation of Musa sp. cultivar Gopi: A palatable banana of Tripura, India. American J. Plant Biol. 3(1):12-16.doi: 10.11648 j.ajpb.20180301.13.

Soniya EV, Banerjee NS and Das MR (2001) Genetic analysis of somaclonal variation among callus derived plants of tomato.Curr. Sci. 80: 1213-1215.

Stover RH and Simmonds NW (1987) Bananas, $3^{\text {rd }}$ ed. Longman Scientific and Technical, New York.

Tomar UK, Negi U, Sinha AK and Dantu PK (2007) An overview of the economic factorsinfluencing micropropagation. My Forest 43: 523-534.

Tsumura Y, Ohba K and Strauss SH (1996) Diversity and inheritance of inter-simple sequence repeat polymorphisms in Douglas fir (Pseudotsuga menziesii) and sugi (Cryptomeria japonica). Theor. Appl. Genet. 92: 40-45.

Yadav AK, Rajbhar YP, Sharma MK, Singh AK and Lal M (2017) Effects of subculturing on in vitro shoot multiplication in banana cultivar "Grand naine". Int. J. Chem. Studies. 5(5): 21072110.

Ying L, Xin Z, Jinji P, Yanxian Q and Yixian X (2011) Molecular assessment of genetic identity and genetic stability in banana cultivar (Musa spp.) from China using ISSR markers. Australian J. Crop Sci. 5 (1): 25-31.

Zerihum D, Vashist U and Boora KS (2009) Molecular characterization of citrus cultivar using DNA markers. Int. J. Biotechnol. Biochem. 5: 271-280.http://www.thefreelibrary.com.

(Manuscript received on 17August, 2019; revised on 25 September, 2019) 